\title{
Measuring Tourists' Emotional Experiences in a cultural site Rita Cannas" ${ }^{* *}$ Daniela Pettinao***
}

\begin{abstract}
The study explores emotions and the engagement with local community as the keys of satisfactory tourists' experience by investigating visitors of an Italian mine village, in which eco-museum and tourist facilities are offered. The methodology is based on a quantitative approach and the main method is a survey analysis, through a questionnaire administrated in situ. The study provides a confirmatory factor analysis in order to test the validity and reliability of the Destination Emotional Scale and the Memorable Tourism Experience Scale. Differently from other implementations, the main findings show that DES does not fit in this sample. However, this study shows the importance of emotions and feelings in the visitors' experience, particularly in the hedonistic and place attachment variables within a specific cultural site.
\end{abstract}

Keyword: Tourists' emotional experiences, destination emotion scale, memorable tourism experience, customer satisfaction, cultural site.

First submission: 13/02/2019, accepted: 12/07/2019

\footnotetext{
*Although the paper is the result of the collaborative work of the two authors, "Introduction" and "1. Literature Review", are attributed to Daniela Pettinao, while "2. Methodology", "3. Findings", and "Conclusions" are attributed to Rita Cannas.

** Corrisponding author: Assistant professor of Management, Department of Business Econonomics, University of Cagliari (Italy). E-mail: rita.cannas@unica.it.

${ }^{* *}$ Associate Professor of Marketing at the Department of Business and Economics, University of Cagliari (Italy). E-mail: pettinao@unica.it.
}

Mercati \& Competitività (ISSN 1826-7386, eISSN 1972-4861), 2019, 3 


\section{Introduction}

In the tourism customer satisfaction field of study, a new area is emerging which focuses on emotional tourism experiences' features. Emotion and satisfaction are a closely related construct. The idea is to consider emotional variables when modelling consumers' satisfaction processes (Bigné et al., 2005; Bigné et al., 2008; Liljander and Strandvik, 1997; Prayag et al., 2013). The analysis of customer satisfaction is considered crucial because it is one of the drivers for customer loyalty (Um, Chon and Ro, 2006). Using this idea, several researchers state that visitor satisfaction at a cultural site (Caldwell, 2002; Martín-Ruiz et al., 2010) is not merely influenced by the technical aspect of the product itself, but also by the emotional, cognitive and social values associated with it.

Tourism experiences are influenced by various dimensions of emotions: for instance, Hosany and Gilbert (2010) identify joy, love, and positive surprise as the three key dimensions of emotional experiences by which is designed the Destination Emotional Scale (DES). Kim and Ritchie (2013) adopt dimensions such as social interaction and local culture, meaningfulness, involvement, happiness, novelty, etc., to conceptualize the construct domains of the Memorable Tourism Experiences Scale (MTES) in which emotions play an essential role.

Despite its relevance, the study of emotions in cultural sites is limited. Many scholars investigate emotions' influence visitor satisfaction and whether this depends on objective variables or not (Del Chiappa et al., 2014). They create models linking tourists' emotional experiences, perceived overall image, satisfaction, and intention to recommend (Prayag et al., 2015).

In our paper we aim to explore the emotions as the backbone of satisfactory tourist experiences in the Rosas Mine Village, an industrial and cultural site pertaining to the Sardinian UNESCO geo-park, in which an eco-museum and other tourist facilities are offered. The village is located in a remote and inner area of Sardinia, which is the second largest island in the Mediterranean, and administratively belongs to Italy.

Considering previous studies about the Rosas Mine Village (Cannas, 2015; Cannas, 2016) we assume that tourists' positive emotions are shaped by and related to the interactions with the local community. Our main aim is to verify whether the DES and the MTES may be implemented in a small cultural site and what outcomes, or insights may derive from this application, in order to enrich the literature about tourist emotional experience. 
Measuring Tourists' Emotional Experiences in a cultural site

\section{Literature Review}

\subsection{Emotion and tourist satisfaction in cultural tourism studies}

Customer satisfaction is a key subject in consumer behaviour literature (Oliver, 1980, 1997) and in tourism literature studies where satisfaction is defined as an emotional reaction extracted from consumption experience (Huang, Weiler, and Assaker, 2015).

Theoretical and empirical studies confirm a link between emotions and satisfaction both in marketing (Ladhari, 2007) and in tourism literature (Yüksel and Yüksel, 2007). For this reason, authors who develop models to understanding customer satisfaction pay particular attention on emotions (Bignè, Andreu and Gnoth, 2005, 2008; Liljander and Strandvik, 1997; Prayag, Hosany and Odeh, 2013).

Emotions and satisfaction have been studied under various perspectives. Walters and Sparks (2012) examine the role that positive emotions have in the process of choosing a tourist destination. Aho (2001), and Mcintosh and Siggs (2005) underline that emotions experienced are an indispensable component of a memorable destination experience. Lee and Kyle (2012) analyse the intensity of emotions in relation to the entire duration of the experience and find out that they are variable throughout the experience. Several authors (Bigné et al., 2005; de Rojas and Camarero, 2008; Hosany and Prayag, 2013) agree that the holiday emotions play a central role in defining the level of satisfaction and influence the tourist's willingness to spend more (Bigné et al., 2005) and to recommend the destination itself (Hosany and Prayag, 2013). At the same time, scholars show that a higher level of tourist satisfaction with a destination will result in higher propensity to recommend the destination (Prayag et al., 2017). Baloglu and colleagues (2019) analyse the role of positive experience on loyalty and influence of emotional well-being. They confirm that a memorable experience also indirectly influences loyalty. Due to their importance, emotions have been used as a segmentation variable for leisure services (Bigné and Andreu, 2004; Bigné et al., 2008). In fact, the analysis of emotions as a segmentation variable is particularly useful in understanding what kind of experience the visitors expect to live during their visit (Thyne, 2001). However, emotions are not considered the only component of customer satisfaction. Several studies argue that both emotion and cognition are components of satisfaction (e.g., Ali et al., 2018) and should properly be considered distinct in the modelling of consumer behaviour in service settings (Wong, 2004). 
Emotions arising from consumption experiences create affective memory traces that consumers process and integrate to form post-consumption evaluations of satisfaction (Westbrook and Oliver, 1991). Several studies focus on marketing analysis (Bagozzi, Gopinath and Nyer, 1999; Ladhari 2007; Liljander and Strandvik 1997; Walsh et al., 2011) and tourism (Bigne, Andreu and Gnoth, 2005; del Bosque and San Martin, 2008; Yuksel and Yuksel, 2007), confirming a relationship between emotions and satisfaction. Oliver (1997) states that satisfaction is a key outcome of positive emotional responses such as pleasure, interest, and joy. According to these studies, positive emotions such as joy (Faullant, Matzler and Mooradian, 2011), happiness, excitement, and pleasure (Grappi and Montanari, 2011) have a favourable influence on tourist satisfaction. To begin with, despite the importance of creating memorable touristic experience, the existing research has not reached the consensus on how to conceptualize and measure quality experience (Huang and Choi, 2019). Despite the relevance of emotion in tourism to understanding customer satisfaction, empirical studies which determine emotional associations tourists attach to destinations remain scarce (Yuksel et al., 2010).

Only recently, emotions have become part of cultural tourism studies that are usually associated with hard-core components (museums, monuments, etc.) (Greffe, 2004; Vecco, 2010). Several studies show how emotional analysis is essential to understand the cultural experience of consumption of cultural tourists (Poria et al., 2006), experience linked to the emotional-cognitive characteristics that make the visitor a participant and an active participant of the visit thanks to the sensory involvement in the site being visited (Oliver, 1997). In fact, among the main motivations that drive the cultural tourist to travel there are education, knowledge accumulation (Gonzalo, 2011; Kerstetter et al., 2001; Poria et al., 2003) and the possibility to try a personal emotion (Poria et al., 2003). In this way, heritage sites exhibit a potential for attracting tourists because learning is a main travel motivation of tourists (Gonzalo, 2011).

A key factor in the cultural tourism studies is the link between involvement, experience quality, satisfaction, and behavioral intentions (recommendation behavior, loyalty). In this regard, Altunel and Erkurt (2015) argue that cultural tourists' involvement positively affects their experience quality. Additionally, they find that experience quality positively influences satisfaction and recommendation behavior and then in turn, satisfaction positively influences a recommendation intention. In other words, they show that a positive and significant involvement of visitors affects a memorable experience. At 
the same time, cultural contact fully mediates the relationship between visitor engagement and memorable experience (Chen and Rahman, 2018).

\subsection{Emotion in tourism destination studies}

Recognizing the lack of research on emotional content of destination experiences, researchers propose that measures of customer satisfaction should include an additional affective component (Martin et al., 2008). Various studies discuss the significance of delight in developing customer satisfaction and loyalty (Hicks et al., 2005; Oliver, 1997; Torres and Kline, 2006), in a specific type of destination (Loureiro, 2010; Kao et al., 2008) and reveal that experiencing quality and satisfaction mediate the relationship between involvement and recommendation intention in the theme parks (Ali et al., 2016) and in the cultural tourism context (Altunel and Erkut, 2015).

The multiplicity of variables linked to the emotional process has made it difficult to measure them. At the same time, the measurement of emotional responses to visitor experiences is a crucial issue for tourism studies (Mauss and Robinson, 2009). To adopt a rigorous scale development process consistent with conventional guidelines in customer experience contest, Hosany and Gilbert (2010) created the Destination Emotion Scale (DES). The DES measures the diversity and intensity of tourists' emotional experiences. It consists of 15 items representing three emotional dimensions: (1) Joy, (2) Love, and (3) Positive Surprise. Joy is associated with positive outcomes such as the realisation of one's goals; love dimension is related to the consumer's propensity to develop an attachment to brands and products; finally, surprise is often characterized as a neutrally valence emotion arising from unexpected occurrences.

In Hosany and Gilbert's (2010) study, the sample was limited to one culture. More recently, using data collected from international tourists visiting other destinations (Hosany et al., 2014; Prayad et al., 2015) further confirmed the DES external validity and they extended original theory of DES to another culture and they related the item to a new construct: place attachment (Scannell and Gifford 2010). Briefly, place attachment refers to the emotional and psychological bonds formed between an individual and a particular spatial setting (Williams et al. 1992). In this study, accordingly to Hosany and Gilbert's (2010) the DES is used to measure tourists' emotional responses.

At the same time, Kim, Ritchie and McCormick (2012) and Kim and Ritchie (2013) developed the Memorable Tourism Experience Scale 
(MTES), based on a research program that identified seven salient dimensions on which to base the MTES: hedonism, refreshment, local culture, meaningfulness, knowledge, involvement, and novelty. The first component, hedonism, refers to pleasure and enjoyment which are significant aspects of tourism experiences. The second component, refreshment, included three items that highlighted personal involvement. The third component, novelty, is derived from many authors (Reder, Donavon and Erickson, 2002; Chandralal and Valenzuela, 2013) and evidence the importance of unusual, atypical, or distinctive events to remember rather than "typical" events. The fourth component represented local culture and it is very important to understanding cultural satisfaction within a cultural site, like the Rosas Mining village. The fifth component, involvement, measures the psychological need to escape from boredom. The sixth component highlighted is acquire new knowledge. The last component represented, meaningfulness, helps to measure the level of happiness and well-being that people acquire during the visit.

With this approach it is crucial to study the interactions between visitors and destination and this study deals with a particular "destination" based on a cultural site and an eco-museum.

Our research questions are addressed, firstly (RQ1) to the validation of the DES model and the variables inspired by the MTES in such a different context, a small site based on cultural activity rather than hedonistic and leisure offering: we assume that tourists emotional experiences can vary and be influenced by the destination's specific attractions and we would like to measure it by two different scales.

Secondly, (RQ2) we aim to test whether and to what extent there are emotional and behavioural differences between local visitors and domestic/international tourists, moving from two considerations: literature offers several studies which analyse different behaviour or attitude by regarding the two segments of local visitors or residents, and tourists; for instance, Moreno and Ritchie (2009) analyse the effect of visitor image on satisfaction with the museum visitation experience by comparing the two mentioned segments; Aicher and colleagues (2015) compares tourists' and locals' motivation to participate in a sport event; Manyiwa and colleagues (2018) focus on the influence of perceived city brand image on emotional attachment to the city. Moreover, the DES and the MTES have been usually implemented in a context of international tourists. For these reasons, we aim to explore possible differences in order to provide new knowledge on this topic. 
Thirdly, (RQ3) we aim to explore if other variables, such as those related to the intention to recommend and promote the visited destination, can contribute to interpreting the visitors' emotions and affection towards the cultural site.

\section{Methodology}

Considering the specific object of our analysis, the emotional experience's spectrum of the visitors of the Rosas Mine village, we decided to implement both the DES (Hosany and Gilbert, 2010) and the MTES (Kim, Ritchie and McCormick, 2012). In our point of view, the two different scales are composed by worthy constructs that together can offer a strong tool of inquire for our setting and can provide us with established knowledge to compare critically our study with the previous ones. This has been a key factor that conditioned our theoretical assumptions at the beginning of our study. Particularly, the former focuses mainly on the emotional sphere as the main threat of tourists' experience: in other words, the scale is addressed to measure the inner emotional involvement of tourists with the destination they had visited. The latter comprises of multifaceted meanings of the tourists' experience, aimed at highlighting the memorable aspects of their experiences, such as the interaction with locals, the acquisition of knowledge, the hedonistic satisfaction and so on, but avoiding some emotional feelings, such as joy and love.

We were aware that the two scales overlapped each other by some similar questions, and that they could have been redundant. Thus, by maintaining the two scales in their original form, the length of the questionnaire would have been unbearable for respondents. For these reasons we chose to adopt the fully DES, and the MTES in a shorter version, by reducing its 24 variables in 17. Specifically, those items grouped into "refreshment" and "meaningfulness" by Kim, Ritchie and McCormick (2012) have not been taken in consideration in the present study.

We assume that both emotions and the engagement with local community (considered in the MTES' items) play a key role on shaping satisfactory tourists' experiences. The Rosas Mine is a peculiar place because, in comparison to other tourism products which encompass both cultural attractions and hedonistic facilities, it used to be a place of hard and painful work.

To some extent we are aware that we are implementing two scales usually applied at destination level in a single tourism product, which means opening a new/different path. We think that the intention to recommend or promote 
the tourism place can be an important issue to test the visitor satisfaction and the visitor emotional involvement.

The study methodology is based on a quantitative approach, and a survey analysis conducted through a questionnaire during the period May-December 2016. Moreover, while preparing and realising the field work, we had meetings with the Rosas Mine Association's staff who manages the cultural site, and also, we did observation and informal interviews with some visitors.

\subsection{The setting}

The Rosas Mine village, located in the small town of Narcao in the SouthWest of Sardinia, used to be an important mining site until the middle of the XX century. After a period of gradual abandonment and collapse of the mining community, the Rosas Mine was restored with the creation, in 1998, of Sardinia's Geomineral park of historical and environmental importance, which was recognized by UNESCO as the first geo-park in the World Geosites Network. After a long time of preparation, the renovation of the exmining site has today established the mining village as an educational, recreational and touristic centre thanks not only to the building restoration, but also to the revival and conservation of a historical memory of great significance (Cannas, 2016). The Rosas Mine Association oversees a complex based on cultural services, catering business, and accommodation facility, which can accommodate a total of 120 guests. In the square where the exwashery stands, there is a bar, while the building that used to house the post office is now a restaurant run by the miners' wives, where guests can sample typical local specialities at lunchtime. The main visiting attraction is the exwashery which is part of the eco-museum, and the mine gallery that may be visited only accompanied by a tour guide. These attractions tell visitors the story of the hard life of miners and their relatives, who spent most of their lives under the ground or working very hard in the washery, including also women and children.

\subsection{Sampling and data collection}

Our primary data were collected through a survey analysis conducted through a questionnaire.

The questionnaire is grouped into four main categories: 1) sociodemographic profile of visitors and visit characteristics; 2) emotional dimensions 
related to joy, love and positive surprise (DES); 3) hedonism, novelty, social interaction, involvement and impressions on local community dimensions, related to MTES; 4) overall visitor satisfaction. The first group, composed by nine items, deals with some generic socio-demographic information, namely gender, age, education, occupation, country of residence, and with specific characteristics of a visit as following: visit frequency, visit party, and visit services enjoyed. The second part is composed by the 15 items of the DES (Hosany and Gilbert, 2010), which are grouped into three categories, joy, love, and positive surprise. The third part focuses on 17 items drawn from the MTES (Kim, Ritchie and McCormick, 2012), in which the main core of questions regards the visitors' perceptions of the local people and the sense of involvement as well as learning of local culture they experienced during the visit. Through eight items, the latest group of questions investigate the overall visit satisfaction by also considering the visitor's propensity to promote actively, among relatives and friends, the visit to the Rosas Mine. Except for the first group of questions, the questionnaire is structured on a 7point Likert scale $(1=$ strongly disagree, $7=$ strongly agree $)$, is composed by overall 49 items, and it ends with an open question regarding eventual suggestions to improving the Rosas Mine Village visitor experiences.

The survey was conducted in situ during the period 19 May-30 December 2016, in two ways: the biggest part of total questionnaires was executed by means of personal interviews conducted by three ad hoc trained students from the University of Cagliari. Thanks to the collaboration with the Rosas Mine's staff, the remaining questionnaires have been self-compiled by respondents (singles, couples and families) who mainly visited the eco-museum and spent some time at the Rosas Mine Village, enjoying accommodation facilities and restaurant services.

Specifically, the survey was conducted during a long period of administration because, after three months (May-July) of the investigation, we collected only 87 valid questionnaires in which the $70 \%$ of our respondents were Sardinian visitors. Considering that the DES and MTES are scales implemented in tourists' contexts, rather than the domestic ones, we extended the survey with the specific aim to involve as many tourists as we could. However, we had to face two main obstacles: (1) to find tourists, and then (2) to engage them with our survey, through the support of the Rosas Mine's staff. Only at the end of the survey administration, we fully realised the difficulty to gather tourists' data in a cultural tourism place, in which the large majority of visitors are locals. 
Notwithstanding, a total of 254 valid questionnaires were collected, representing $5 \%$ of the total visitors in the chosen period. Most of the questionnaires were drawn from respondents by face to face interviews, and a fewer of them have been self-compiled by visitors.

\section{Findings}

In the first part of the questionnaire we dealt with the demographic profile and trip characteristics of our respondents, as shown in Table 1. Descriptive statistics on the sample show that the Rosas Mine Village visitors are mainly women $(54.3 \%)$, adult people $(48.4 \%)$, employed in public and private organisations (41.3\%), and Sardinians (61.4\%). Also, they are well-educated (with $42.1 \%$ college graduate, $4.7 \%$ graduate and $21.7 \%$ postgraduate), travel with family $(37.4 \%)$, and visit for the first time the Rosas Mine Village (94.1\%), particularly the mine gallery (94.1\%) and the eco-museum (83.1\%). Only a few respondents are clients of the Rosas Mine's scattered hotel. From the first part of the questionnaire (Table 1), emerges a peculiar characterisation of this place: tourists coming from the rest of Italy are only $38.6 \%$, and particularly those coming from abroad are a very few. In other words, the cultural site we have investigated does not represent an international tourist sample, because most of the respondents are Sardinian daily trippers.

This characteristic is fully coherent with the information we gathered from the Rosas Mine Village managers during the field-work. This site is not well-marketed overseas, because the Rosas Mine Association' shareholders prefer to adopt a "lower profile" by hosting Sardinian groups of visitors through local and selected networks, such as scholar institutions, sports associations, rather than promoting the village within tour operators or online channels. For instance, on the Rosas Mine Village website the option to book on-line is absent, and the same holds valid on other online tour operators, such as booking.com. 
Measuring Tourists' Emotional Experiences in a cultural site

Table 1 - Demographic profile and trip characteristics of respondents

\begin{tabular}{|c|c|c|c|}
\hline Variable & Category & $\mathrm{N}$. & $\%$ \\
\hline \multirow[t]{2}{*}{ Gender } & Female & 138 & 54.3 \\
\hline & Male & 116 & 45.7 \\
\hline \multirow[t]{7}{*}{ Age } & $<18$ & 22 & 8.7 \\
\hline & $18-24$ & 46 & 18.1 \\
\hline & $25-34$ & 6 & 2.4 \\
\hline & $35-44$ & 11 & 4.3 \\
\hline & $45-54$ & 58 & 22.8 \\
\hline & $55-64$ & 65 & 25.6 \\
\hline & $>64$ & 46 & 18.1 \\
\hline \multirow[t]{2}{*}{ Place of residence } & Sardinia & 156 & 61.4 \\
\hline & Overseas & 98 & 38.6 \\
\hline \multirow[t]{7}{*}{ Education level } & Primary school & 16 & 6.3 \\
\hline & Secondary school & 36 & 14.2 \\
\hline & College graduate & 107 & 42.1 \\
\hline & Graduate & 12 & 4.7 \\
\hline & Postgraduate & 48 & 18.9 \\
\hline & Doctoral degree & 7 & 2.8 \\
\hline & Others & 1 & 0.4 \\
\hline \multirow[t]{6}{*}{ Job position } & Employed private sector & 62 & 24.4 \\
\hline & Employed public sector & 43 & 16.9 \\
\hline & Self-employed & 46 & 18.1 \\
\hline & Retired & 46 & 18.1 \\
\hline & Student & 30 & 11.8 \\
\hline & Other & 27 & 10.6 \\
\hline \multirow[t]{2}{*}{ Number of previous visit } & No previous visit & 229 & 90.2 \\
\hline & Previous visit & 25 & 9.8 \\
\hline \multirow[t]{6}{*}{ Travel companion } & Alone & 3 & 1.2 \\
\hline & Partner & 49 & 19.3 \\
\hline & Family & 95 & 37.4 \\
\hline & Friends & 44 & 17.3 \\
\hline & Group & 57 & 22.4 \\
\hline & Other & 6 & 2.4 \\
\hline \multirow[t]{5}{*}{ Activity/Service (multiple answers) } & Eco-museum & 211 & 83.1 \\
\hline & Mine Gallery & 239 & 94.1 \\
\hline & Restaurant & 118 & 46.5 \\
\hline & Bar & 15 & 6.0 \\
\hline & Hotel & 30 & 11.8 \\
\hline
\end{tabular}

131 


\subsection{RQ1: Validation of the DES and the MTES}

While focussing on emotional and memorable experiences' responses, we consider the validity and reliability of the DES (Hosany and Gilbert, 2010; Hosany et al., 2014; Prayag et al., 2015) and the MTES (Kim et al., 2012; Kim and Ritchie, 2013) which have been already tested in previous studies.

Specifically, on the basis of prior tourism studies, we expect that the DES impacts on emotional and behavioural individual intentions, as well as the variables borrowed by the MTES. Following the above-mentioned implementations, our sample has been tested by a confirmatory factor analysis (CFA) using the open source software $\mathrm{R}$ with the package Lavaal, and AMOS to estimate the structural equation models (SEM) (Table 3).

Table 2 - Items descriptions and measurement model results for the DES and the MTES

\begin{tabular}{|c|c|c|c|c|}
\hline Scale items description & $\begin{array}{l}\text { Standardized } \\
\text { Factor Loading }\end{array}$ & $\begin{array}{l}\text { Composite } \\
\text { reliabilities }\end{array}$ & $\begin{array}{l}\text { Average } \\
\text { variance } \\
\text { extracted }\end{array}$ & $\begin{array}{l}\text { Square } \\
\text { multiple } \\
\text { correlation } \\
\left(\mathbf{R}^{2}\right)\end{array}$ \\
\hline \multicolumn{5}{|l|}{ DES } \\
\hline Joy & & 0.85 & 0.54 & \\
\hline I feel cheerful & 0.75 & & & 0.56 \\
\hline I feel a sense of delight & 0.74 & & & 0.55 \\
\hline I feel a sense of enthusiasm & 0.55 & & & 0.30 \\
\hline I feel a sense of joy & 0.85 & & & 0.73 \\
\hline I feel a sense of pleasure & 0.76 & & & 0.58 \\
\hline Love & & 0.85 & 0.56 & \\
\hline I feel a sense of affection & 0.74 & & & 0.55 \\
\hline I feel a sense of caring & 0.81 & & & 0.66 \\
\hline I feel a sense of love & 0.85 & & & 0.72 \\
\hline I feel a sense of tenderness & 0.78 & & & 0.62 \\
\hline I feel warm-hearted & 0.50 & & & 0.25 \\
\hline Positive surprise & & 0.84 & 0.54 & \\
\hline I feel a sense of astonishment & 0.81 & & & 0.66 \\
\hline I feel a sense of amazement & 0.88 & & & 0.78 \\
\hline I feel fascinated & 0.61 & & & 0.37 \\
\hline I feel a sense of inspiration & 0.51 & & & 0.26 \\
\hline I feel a sense of surprise & 0.79 & & & 0.62 \\
\hline
\end{tabular}

132 
Measuring Tourists' Emotional Experiences in a cultural site

\begin{tabular}{|c|c|c|c|c|}
\hline \\
\hline \multicolumn{2}{|l|}{$\frac{\text { MTES }}{\text { Hedonism }}$} & \multirow[t]{2}{*}{0.80} & \multicolumn{2}{|l|}{0.52} \\
\hline Thrilled about having a new experience & 0.60 & & & 0.36 \\
\hline Indulged in the activities & 0.65 & & & 0.43 \\
\hline Really enjoyed this tourism experience & 0.83 & & & 0.69 \\
\hline Exciting & 0.77 & & & 0.59 \\
\hline Novelty & & 0.84 & 0.58 & \\
\hline Once-in-a lifetime experience & 0.69 & & & 0.48 \\
\hline Unique & 0.74 & & & 0.55 \\
\hline Different from previous experiences & 0.81 & & & 0.66 \\
\hline Experienced something new & 0.79 & & & 0.62 \\
\hline Local culture & & 0.78 & 0.55 & \\
\hline $\begin{array}{l}\text { The local people left me with a good impres- } \\
\text { sion }\end{array}$ & 0.73 & & & 0.54 \\
\hline Closely experienced the local culture & 0.64 & & & 0.41 \\
\hline $\begin{array}{l}\text { Local people in the Rosas village were } \\
\text { friendly }\end{array}$ & 0.84 & & & 0.71 \\
\hline Involvement & & 0.84 & 0.65 & \\
\hline $\begin{array}{l}\text { I visited a place where I really wanted to go } \\
\text { to }\end{array}$ & 0.78 & & & 0.60 \\
\hline $\begin{array}{l}\text { I enjoyed activities which I really wanted to } \\
\text { do }\end{array}$ & 0.84 & & & 0.70 \\
\hline $\begin{array}{l}\text { I was interested in the main activities of this } \\
\text { experiences } t\end{array}$ & 0.80 & & & 0.63 \\
\hline Knowledge & & 0.74 & 0.50 & \\
\hline $\begin{array}{l}\text { The visit enhanced my personal develop- } \\
\text { ment }\end{array}$ & 0.81 & & & 0.65 \\
\hline I learned something new about myself & 0.65 & & & 0.43 \\
\hline I learned about the local culture & 0.65 & & & 0.42 \\
\hline
\end{tabular}

Since the significance of $\chi^{2}$ test is highly dependent on the number of degrees of freedom, the ratio of the $\chi^{2}$ test to the degree of freedom was calculated $(\chi 2 / \mathrm{df})$. As stated by Hoe (2008), if the ratio of the $\chi^{2}$ to the degree of freedom is 3 or less, a model is judged to be acceptable. Then, three goodness-of-fit statistics were utilized: the comparative fit index (CFI), TuckerLewis index (TLI or non-normed fit index NNFI), and the root mean square error of approximation (RMSEA). 
Rita Cannas, Daniela Pettinao

Table 3 - Measurement of the DES and the MTES results: confirmatory factors analysis Goodness-of-fit statistic index

\begin{tabular}{l|l|l}
\hline Measures & DES & MTES \\
\hline$X^{2}$ & 393.40 & 322.92 \\
\hline $\mathrm{df}$ & 87 & 109 \\
\hline$p$-value & 0.00 & 0.00 \\
\hline$X^{2 / d f}$ & 4.52 & 2.96 \\
\hline CFI & 0.85 & 0.90 \\
\hline NFI & 0.82 & 0.86 \\
\hline TLI & 0.82 & 0.87 \\
\hline RMR & 0.24 & 0.10 \\
\hline RMSEA & 0.12 & 0.09 \\
\hline
\end{tabular}

Note: $\mathrm{CFI}=$ comparative fit index; $\mathrm{NFI}=$ normed fit index;

$\mathrm{TLI}=$ Tucker-Lewis index; RMR = root mean square residual;

RMSEA = root mean square error of approximation.

Our results show that the DES has not been validated (Table 2). Particularly, the $\chi^{2}$ to the degree of freedom is over 3 . Only the variables drawn from the MTES provided a good fit. This suggests that the DES does not seem the best scale to be implemented in such a peculiar contest in which emotions like joy and love, do not play a key role in shaping the tourists' experiences.

From the respondents' answers to the open questions of the questionnaire and in some informal interviews, we realised during our in-field investigation that we gathered interesting feedbacks: we found out that visitors felt emotionally touched by the visit in the co-museum and the mining gallery. They experienced a deep sense of emotional bond with the local community that does not match the DES variables.

\subsection{RQ2: Emotional and behavioural differences between locals and domestic/international tourists}

To answer our second research question, for which we aim to test whether and to what extent there are emotional and behavioural differences between local visitors and domestic/international tourists, we have broken down our data set into two sub-groups of respondents: Sardinians visitors, named "locals", and the other tourists, called "overseas tourists". Particularly, we were intrigued in testing if the segment of overseas tourists could be characterised 
by higher positive feelings and emotions involvement while visiting the Rosas Mine Village, in comparison to the local segment, composed by only Sardinian visitors. Potential differences emerged by preliminary observations and direct interactions we had had with some Rosas Mine Village visitors along the initial stage of the survey administration. Particularly, the Sardinian visitors, composed mainly by elderly people, expressed moderate emotional levels of appreciation and satisfaction. Instead, we gathered enthusiastic comments by overseas tourists who visited Sardinia for sunbathing activities and then discovered something unexpected in the Rosas Mine Village, in which "another Sardinia" tells the story of local communities (usually the Sardinian coastlines do not tell any story because there were no local communities placed there before the tourism development). Therefore, our research question was grounded partially on previous studies in which scholars have compared tourists' and locals' emotions (Moreno and Ritchie, 2009), motivations (Aicher et al., 2015) perceptions (Manyiwa et al., 2018), and partially supported by the feedbacks we gathered in situ, before starting the survey administration.

The analysis shows some differences in the two sub-groups: locals' responses are comprised mainly in the central part of the questionnaire, avoiding the extremity such as "strongly disagree" or "strongly agree". Instead, the overseas tourists express the highest levels of emotional involvement, as well as the lower ones in their visiting experience at the Rosas Mine Village.

To show the differences of the two sub-groups we computed the distribution of the answers and then the asymmetry and the kurtosis related to the DES. In Figure 1, on the x-axis, values of asymmetry are reported; while the y-axis shows kurtosis values.

Negative skewness means that hypothesizing a normal distribution of variables, the top of the curve slopes on the right side, is attesting that the highest values of appreciation/satisfaction are expressed. High values of kurtosis mean that preferences are more concentrated in low values. Thus, a negative asymmetry joined with higher kurtosis shows items for which respondents have expressed highest appreciation, and also reveal the highest concentration of positive variables.

Figure 1 shows how the skewness related to the overseas responses has the most negative values in comparison to those related to the locals; this means that the answers of the overseas are more inclined toward the highest values of the Likert scale (1-7). In other words, our assumption which supports the RQ2 has been confirmed. 
Rita Cannas, Daniela Pettinao

Figure 1 - Distribution of DES items per sub-groups of respondents by asymmetry and kurtosis analysis

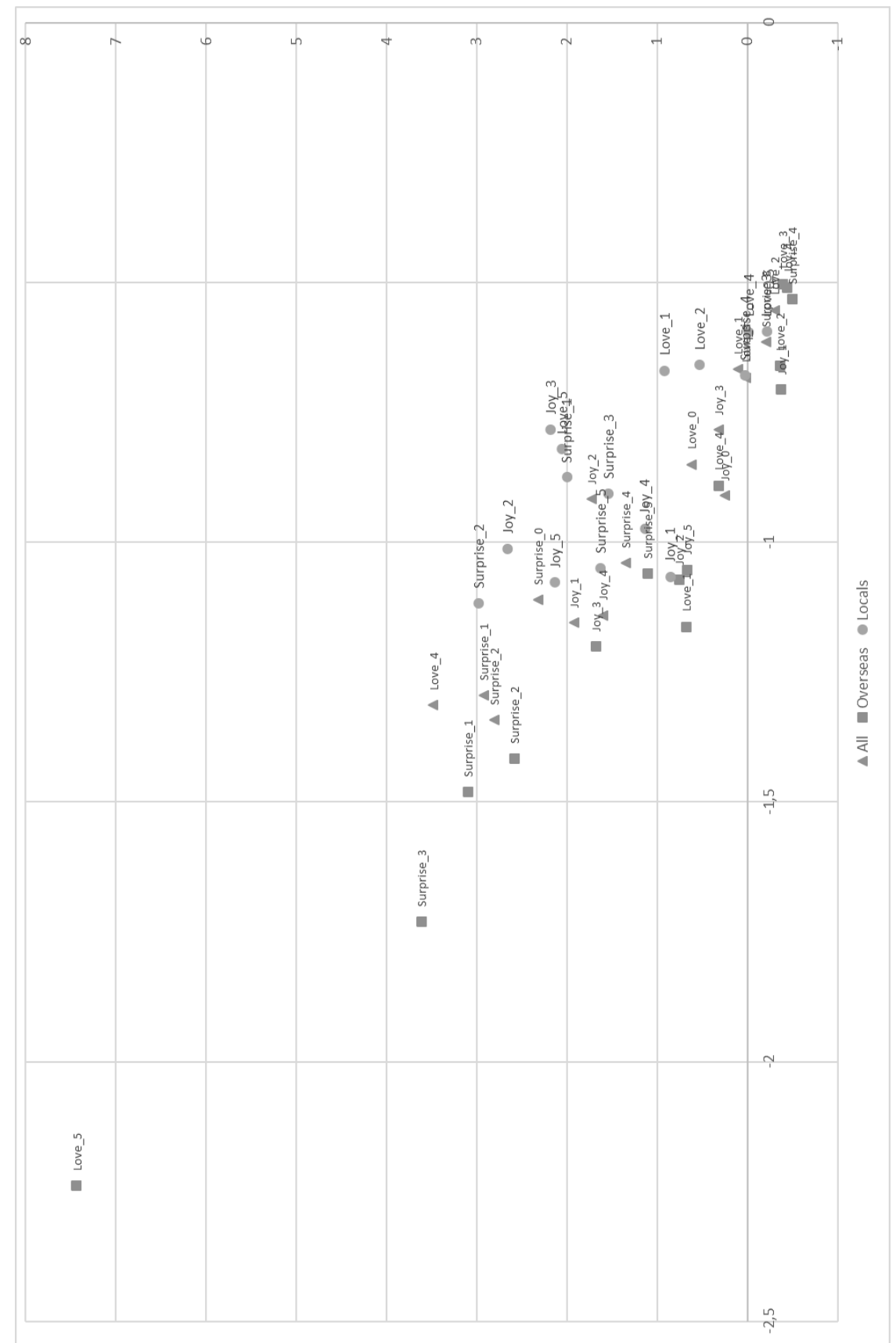

136

Copyright $\odot$ FrancoAngeli

This work is released under Creative Commons Attribution - Non-Commercial - NoDerivatives License.

For terms and conditions of usage please see: http://creativecommons.org 
Additionally, we computed the responses average of the two sub-groups and then we calculated the standard deviation in order to measure the variations from the mean related to each item. Again, we found out that within the 40 items composing the questionnaire (excluding the 9 general items related to the first part of the questionnaire), only 10 have shown that the averages of locals' responses were higher than those of the tourists. Moreover, by computing the standard deviation of the average responses and comparing the results in the two sub-groups of respondents, we found that locals' responses were more homogenies than the tourists' ones.

We also computed the Student's T-Test to determine if there is a significant difference between the means of two groups, in this case the "locals" and the "tourists". With p-value of 0.05 or less, we can reject the null hypothesis, meaning that the two sub-groups show differences. On the sixth column (Table 4), numbers underlined in bold show a p-value under 0.05 , and those highlighted in italic have the p-value between 0.05 and 0.1 Basically, the two sub-groups are clearly different from each other in 11 of 40 items, and show potential differences in 7 items. Again, our hypothesis seems to be confirmed, but we recognise that two larger sub-groups of our sample would have provided more solid results.

Table 4 - Average, standard deviation and p-value of locals' and tourists' responses

\begin{tabular}{|c|c|c|c|c|c|}
\hline \multirow[t]{2}{*}{ Items } & \multicolumn{2}{|c|}{ Locals' responses } & \multicolumn{2}{|c|}{ Tourists' responses } & \multirow[t]{2}{*}{ p-value } \\
\hline & Average & st. dev & Average & st. dev & \\
\hline Joy_1 & 4.80 & 1.43 & 4.62 & 1.68 & 0,385 \\
\hline Joy_2 & 5.29 & 1.10 & 5.09 & 1.54 & 0,273 \\
\hline Joy_3 & 5.60 & 1.01 & 5.85 & 1.08 & 0,073 \\
\hline Joy_4 & 4.71 & 1.33 & 4.41 & 1.65 & 0,136 \\
\hline Joy_5 & 5.04 & 1.17 & 4.91 & 1.61 & 0,468 \\
\hline Love_1 & 4.66 & 1.36 & 5.01 & 1.65 & 0,081 \\
\hline Love_2 & 4.44 & 1.50 & 4.40 & 1.77 & 0,860 \\
\hline Love_3 & 4.10 & 1.63 & 4.10 & 1.69 & 0,978 \\
\hline Love_4 & 4.47 & 1.63 & 4.87 & 1.71 & 0,067 \\
\hline Love_5 & 5.65 & 1.03 & 6.09 & 1.12 & 0,002 \\
\hline Surprise_1 & 5.45 & 1.11 & 5.67 & 1.26 & 0,149 \\
\hline Surprise_2 & 5.60 & 1.08 & 5.59 & 1.35 & 0,979 \\
\hline Surprise_3 & 5.78 & 1.08 & 5.86 & 1.34 & 0,612 \\
\hline Surprise_4 & 4.70 & 1.64 & 4.69 & 1.70 & 0,982 \\
\hline
\end{tabular}


Rita Cannas, Daniela Pettinao

\begin{tabular}{|c|c|c|c|c|c|}
\hline Surprise_5 & 5.31 & 1.30 & 5.40 & 1.45 & 0,641 \\
\hline Edonism_1 & 5.77 & 0.90 & 5.89 & 1.06 & 0,361 \\
\hline Edonism_2 & 5.76 & 0.93 & 6.03 & 0.79 & 0,013 \\
\hline Edonism_3 & 5.75 & 0.93 & 6.03 & 1.04 & 0,031 \\
\hline Edonism_4 & 5.73 & 0.86 & 5.87 & 1.07 & 0,288 \\
\hline Novelty_1 & 4.32 & 2.03 & 4.46 & 2.15 & 0,609 \\
\hline Novelty_2 & 5.03 & 1.43 & 5.22 & 1.64 & 0,341 \\
\hline Novelty_3 & 5.15 & 1.45 & 5.60 & 1.20 & 0,008 \\
\hline Novelty_4 & 5.21 & 1.45 & 5.42 & 1.48 & 0,263 \\
\hline Local_culture_1 & 5.84 & 1.04 & 6.26 & 0.98 & 0,001 \\
\hline Local_culture_2 & 4.60 & 1.58 & 5.38 & 1.59 & 0,000 \\
\hline Local_culture_3 & 5.55 & 1.10 & 6.10 & 1.10 & 0,000 \\
\hline Involvment_1 & 5.56 & 1.16 & 5.92 & 0.88 & 0,006 \\
\hline Involvment_2 & 5.54 & 1.07 & 5.70 & 1.17 & 0,257 \\
\hline Involvment_3 & 5.67 & 1.00 & 5.78 & 1.13 & 0,462 \\
\hline Knowledge_1 & 5.35 & 1.22 & 5.86 & 1.06 & 0,001 \\
\hline Knowledge_2 & 4.70 & 1.66 & 4.79 & 1.53 & 0,670 \\
\hline Knowledge_3 & 5.63 & 1.23 & 6.14 & 0.87 & 0,000 \\
\hline Over_all_1 & 6.28 & 0.79 & 6.43 & 0.61 & 0,085 \\
\hline Over_all_2 & 6.11 & 0.78 & 6.29 & 0.79 & 0,082 \\
\hline Over_all_3 & 5.54 & 1.21 & 5.18 & 1.47 & 0,044 \\
\hline Over_all_4 & 6.13 & 1.01 & 6.24 & 0.94 & 0,351 \\
\hline Over_all_5 & 6.22 & 0.93 & 6.43 & 0.80 & 0,057 \\
\hline Over_all_6 & 6.23 & 0.94 & 6.38 & 0.78 & 0,178 \\
\hline Over_all_7 & 5.16 & 1.68 & 4.88 & 1.98 & 0,241 \\
\hline Over_all_8 & 4.99 & 1.60 & 4.58 & 1.76 & 0,062 \\
\hline
\end{tabular}

\subsection{RQ3: Intention to recommend and promote the visited destina- tion as the satisfactory level of the tourism experiences}

The high level of the overall satisfaction of the visitors at the Rosas Mine Village is well expressed in Table 5 from which it emerges that in the first two items ("I liked the RMV" and "my experience at RMV has been satisfying") not a single dislike was expressed by the 254 respondents. Almost a half of the respondents expresses a high satisfaction. 
When we began our study, we thought that the overall visitors' satisfaction could have been correlated also with positive feelings, such as joy, love, and the sense of surprise. Instead, we did not find such strong ties among these variables and the overall visitors' satisfaction, probably because of the specific nature of the mine site, and/or because of the small sample size in which the majority of visitors are locals.

Table 5 - Percentage distribution of responses of overall satisfaction items

\begin{tabular}{|c|c|c|c|c|c|c|c|}
\hline $\begin{array}{l}\text { The overall satisfaction } \\
\text { items }\end{array}$ & $\begin{array}{l}\text { Strongly } \\
\text { disagree }\end{array}$ & Disagree & $\begin{array}{l}\text { Slightly } \\
\text { disagree }\end{array}$ & Neutral & $\begin{array}{c}\text { Slightly } \\
\text { agree }\end{array}$ & Agree & $\begin{array}{l}\text { Strongly } \\
\text { agree }\end{array}$ \\
\hline $\begin{array}{l}\text { (1) I liked the Rosas Mining } \\
\text { Village (RMV) }\end{array}$ & 0.0 & 0.0 & 0.0 & 1.2 & 11.8 & 39.4 & 47.6 \\
\hline $\begin{array}{l}\text { (2) My experience at RMV } \\
\text { has been satisfying }\end{array}$ & 0.0 & 0.0 & 0.8 & 1.6 & 14.2 & 46.1 & 37.4 \\
\hline $\begin{array}{l}\text { (3) I would revisit RMV to } \\
\text { enjoy of services/activities }\end{array}$ & 2.8 & 0.0 & 6.3 & 9.1 & 29.1 & 32.3 & 20.5 \\
\hline $\begin{array}{l}\text { (4) I will recommend RMV to } \\
\text { other people }\end{array}$ & 0.8 & 0.4 & 0.4 & 3.5 & 12.2 & 39.4 & 43.3 \\
\hline $\begin{array}{l}\text { (5) I will say positive things } \\
\text { about RMV to other people }\end{array}$ & 0.4 & 0.0 & 0.8 & 2.8 & 9.8 & 36.6 & 49.6 \\
\hline $\begin{array}{l}\text { (6) I will encourage friends } \\
\text { and relatives to visit RMV }\end{array}$ & 0.4 & 0.0 & 0.4 & 3.1 & 10.6 & 36.6 & 48.8 \\
\hline $\begin{array}{l}\text { (7) I will promote actively } \\
\text { RMV through my social me- } \\
\text { dia page }\end{array}$ & 9.8 & 0.0 & 5.1 & 20.5 & 13.8 & 26.4 & 24.4 \\
\hline $\begin{array}{l}\text { (8) I will actively follow the } \\
\text { social media page of RMV }\end{array}$ & 9.1 & 0.8 & 6.3 & 20.1 & 24.4 & 24.0 & 15.4 \\
\hline
\end{tabular}

Positive correlation between the overall satisfaction items and those of DES and MTES have been explored (Table 6). Particularly, we have found correlations between the overall satisfaction and two dimensions of the MTES: hedonism and involvement. We interpreted such results by considering (as previously shown in Table 2) that visitors expressed the highest score at the item "Really enjoyed this tourism experience" comprises in the hedonistic items, and in the "I enjoyed activities which I really wanted to do" included in the involvement items. We deduce that visitors are emotionally linked to the Rosas Mining Village; they really appreciate the visit experience, but maybe for the specific characteristics of the place, they do not experience a strong sense of joy or of love. 
Table 6 - Index of correlation between the DES and the MTES items with the Overall satisfaction

\begin{tabular}{lrrrrrrrr}
\hline & Overall 1 & Overall 2 & Overall 3 & Overall 4 & Overall 5 & Overall 6 & Overall 7 & Overall 8 \\
\hline Joy & 0.20 & 0.31 & 0.37 & 0.24 & 0.26 & 0.22 & 0.28 & 0.29 \\
Love & 0.21 & 0.35 & 0.37 & 0.31 & 0.34 & 0.31 & 0.38 & 0.36 \\
Surprise & 0.37 & 0.45 & 0.42 & 0.42 & 0.41 & 0.37 & 0.32 & 0.36 \\
Hedonism & $\mathbf{0 . 5 5}$ & $\mathbf{0 . 6 2}$ & 0.40 & 0.54 & $\mathbf{0 . 5 7}$ & $\mathbf{0 . 5 7}$ & 0.35 & 0.34 \\
Novelty & 0.28 & 0.35 & 0.35 & 0.27 & 0.27 & 0.28 & 0.43 & 0.44 \\
Local Culture & 0.37 & 0.40 & 0.41 & 0.31 & 0.40 & 0.36 & 0.30 & 0.35 \\
Involvement & 0.50 & 0.57 & 0.46 & 0.50 & 0.56 & 0.54 & 0.30 & 0.33 \\
Knowledge & 0.37 & 0.51 & 0.40 & 0.39 & 0.44 & 0.44 & 0.44 & 0.45 \\
\hline
\end{tabular}

Note: the overall satisfaction items are fully reported in Table 4; e.g, Overall 1 = I liked the Rosas Mining Village

\section{Conclusions}

In the specific context of a cultural site where in the literature the emotional approach to visitor satisfaction is scarce, our findings show different levels of appreciation expressed by respondents who visited the Rosas Mining Village. The variables which positively impact on visitors' satisfaction are heterogenic and belong to a mix of emotional, hedonistic, local culture and place attachment items. Specifically, the application of two scales (corresponding to our RQ1), the fully DES and the revisited MTES, reveals that the former seems not the best tool to measure the emotional involvement of visitors in a cultural site, in this case the Rosas Mining Village. Instead, most of the variables of the MTES show a better correspondence to the emotional involvement felt by the visitors of this cultural site.

We think that feelings such as "joy" and "love", applied in tourism leisure study may vary from culture to culture. In other words, we argue that this mismatch (referred to the DES validation) may be due to the ontological assumption of DES scholars for which tourists experience universal feelings wherever they are - by implicitly assuming that emotions are independent from the specific attractions of the investigated tourism destinations - in our study, emotions seem to be influenced by the specific characteristics of the place, especially when this is small and related to single attractions. However, we find out that our sample of 254 respondents is mainly composed by local visitors who tend to feel a lower level of emotions in comparison to the overseas (domestic and international) ones and this could have impacted on 
the DES application. We invite scholars to further investigations that can clarify better this point and confirm or reject our outcomes.

Moreover, we have analysed the sub-groups of locals and tourists and found differences in their behaviours and attitude to feel emotions (RQ2) but we recognise that this outcome should be verified in further investigations considering a greater number of tourists in the sample.

We believe that the composition and small size of our sample represents the first limitation of our research. The second one consists of the methodological approach that we have adopted. At the beginning of our in-field research, we gathered positive emotional feedbacks from visitors which encouraged us to apply established scales at international level (such as DES and MTES), through a survey analysis. Beyond the structure of the sample, we believe that a qualitative approach could have helped us in investigating and critically deepen the nature of constructs by which emotions embed satisfactory tourists' experience in a cultural site. In fact, locals and tourists have shown a high level of satisfaction and involvement in visiting the Rosas Mine village (as treated in RQ3), but perhaps the investigated items could have been proposed by different words or expressed by different emotions such as, for instance, poignancy.

Notwithstanding the research limitations, our findings suggest to scholars to consider a more tailored scale when measuring emotions and satisfactory experiences in a single tourism product - particularly, when it is based on cultural attractions - rather than a destination. Finally, our study contributes to enrich the empirical studies by reaffirming the importance of emotions in the visitors' experience. We believe that this outcome should be taken into consideration by managers when designing, planning and running their business in such peculiar places like small destinations or single attractions, based on local cultural memory.

\section{References}

Aho S.K. (2001). Towards a General Theory of Touristic Experiences: Modeling Experience Process in Tourism. Tourism Review, 56(3): 33-37. DOI: 10.1108/eb058368.

Aicher T.J., Karadakis K. and Eddosary M.M. (2015). Comparison of sport tourists' and locals' motivation to participate in a running event. International Journal of Event and Festival Management, 6(3). DOI: 10.1108/IJEFM-03-2015-0011.

Ali F., Kim W., Li J. and Jeon H. (2018). Make it delightful: Customers' experience, satisfaction and loyalty in Malaysian theme parks. Journal of Destination Marketing and Management, 7. DOI: 1-11. 10.1016/j.jdmm.2016.05.003. 
Altunel M.C. AND Erkut B. (2015). Cultural tourism in Istanbul: The mediation effect of tourist experience and satisfaction on the relationship between involvement and recommendation intention. Journal of Destination Marketing and Management, 4: 213-221. DOI: 10.1016/j.jdmm.2015.06.003.

Bagozzi R.P., Gopinath M. and Nyer P.U. 1999. The role of emotions in marketing. Journal of the Academy of Marketing Science, 27(2): 184-206. DOI: 10.1177/0092070399272005.

Baloglu S., Busser J. and Cain L. (2019) Impact of experience on emotional wellbeing and loyalty, Journal of Hospitality Marketing and Management, 28(4): 427-445, DOI: 10.1080/19368623.2019.1527269.

Bigné J.E., Andreu L. and Gnoth J. (2008). The impact of experiential consumption cognitions and emotions on behavioral intentions. Journal of Service Marketing, 22(4): 303-315. DOI: 10.1108/08876040810881704.

Bigné J.E., Andreu L. and Gnoth J. (2005). The theme park experience: an analysis of pleasure, arousal and satisfaction. Tourism Management, 26(6): 833-844. DOI: 10.1016/j.tourman.2004.05.006.

Bigné J.E. and Andreu L. (2004). Emotions in Segmentation. Annals of Tourism Research, 31(3): 682-96. DOI: 10.1016/j.annals.2003.12.018.

Caldwell N. (2002). (Rethinking) the measurement of service quality in museums and galleries. International Journal of Nonprofit and Voluntary Sector Marketing, 7(2): 161-171. DOI: 10.1002/nvsm.176.

Cannas R. (2016) The Sustainable Tourism Management of Cultural Heritage: the case of the Rosas Mine in Sardinia. Almatourism Journal of Tourism, Culture and Territorial Development, 7(14): 38-59. DOI: 10.6092.

Cannas R. (2015). Binomio vincente tra Heritage e sviluppo sostenibile: il caso della Miniera Rosas in Sardegna. Sinergie Proceedings, 289-300. DOI: 10.7433/SRECP.2015.18.

Chandralal L. and Valenzuela F. (2013). Exploring Memorable Tourism Experiences: Antecedents and Behavioural Outcomes. Journal of Economics, Business and Management, 1(2): 177-81. DOI: 10.7763/joebm.2013.v1.38.

Chen H. and Rahman I. (2018). Cultural tourism: An analysis of engagement, cultural contact, memorable tourism experience and destination loyalty. Tourism Management Perspectives, 26: 153-163. DOI: 10.1016/j.tmp.2017.10.006.

de Rojas C. and Camarero C. (2008). Visitor's experience, mood and satisfaction in a heritage context: Evidence from an interpretation center. Tourism Management, 29(3): 525-537. DOI: 10.1016/j.tourman.2007.06.004.

del Bosque I.R. and San Martin H. (2008). Tourist Satisfaction a Cognitive-Affective Model. Annals of Tourism Research, 35(2): 551-73. DOI: 10.1016/j.annals.2008.02.006

Del Chiappa G., Andreu L. and Gallarza M.G. (2014). Emotions and visitors' satisfaction at a museum. International Journal of Culture Tourism and Hospitality Research, 8(4): 420-431. DOI: 10.1108/ijcthr-03-2014-0024.

Faullant R., Matzler, K. and Mooradian, T.A. (2011). Personality, Basic Emotions, and Satisfaction: Primary Emotions in the Mountaineering Experience. Tourism Management, 32(6): 1423-30. DOI: 10.1016/j.tourman.2011.01.004. 
Gonzalo R.P.A. (2011). Packaging heritage tourism: A value chain approach for creating heritage tourism experiences. International Journal of Agricultural Travel and Tourism, 2(1): 71-86.

Grappi S. and Montanari F. (2011). The Role of Social Identification and Hedonism in Affecting Tourist Re-patronizing Behaviors: The Case of an Italian Festival. Tourism Management, 32(5): 1128-40. DOI: 10.1016/j.tourman.2010.10.001.

Greffe X. (2004). Is heritage an asset or a liability? Journal of Cultural Heritage, 5 : 301-309. DOI: 10.1016/j.culher.2004.05.001.

Hicks J.M., Page T.J., Behe B.K., Dennis J.H. and Fernandez R.T. (2005). Delighted consumers buy again. Journal of Consumer Satisfaction, Dissatisfaction and Complaining Behavior, 18: 94-104. DOI: 10.21273/hortsci.40.4.1063e.

Hoe S.L. (2008). Issues and Procedures in Adopting Structural Equation Modeling Technique. Journal of Applied Quantitative Methods, 3(1): 76-83.

Hosany S. and Gilbert D. (2010). Measuring tourists' emotional experiences toward hedonic holiday destinations. Journal of Travel Research, 49(4): 513-526. DOI: 10.1177/0047287509349267.

Hosany S., Prayag G., Deesilatham S., Cauševic S. and Odeh K. (2014). Measuring tourists' emotional experiences: Further validation of the destination emotion scale. Journal of Travel Research, 54(4): 482-495. DOI: 10.1177/ 0047287514522878.

Hosany S. and Prayag G. (2013). Patterns of Tourists' Emotional Responses, Satisfaction, and Intention to Recommend. Journal of Business Research, 66(6): 73037. DOI: 10.1016/j.jbusres.2011.09.011.

Huang S., Weiler, B. and Assaker G. (2015). Effects of interpretive guiding outcomes on tourist satisfaction and behavioral intention. Journal of Travel Research, 54(3): 344-358. DOI: 10.1177/0047287513517426.

Huang S. and Choi H.C. (2019) Developing and validating a multidimensional tourist engagement scale (TES). The Service Industries Journal, 39(7-8): 469-497, DOI: $10.1080 / 02642069.2019 .1576641$.

Kao M.C., Patterson I., Scott N. and Li C.K. (2008). Motivations and satisfactions of Taiwanese tourists who visit Australia: An exploratory study. Journal of Travel and Tourism Marketing, 24(1): 17-33. DOI: 10.1300/j073v24n01_02.

Kerstetter D.L., Confer J.J., and Graefe A.R. (2001). An exploration of the specialization concept within the context of heritage tourism. Journal of Travel Research, 39(3): 267-274. DOI: 10.1177/004728750103900304.

Kim J. and Ritchie J.R.B. (2013). Cross-Cultural Validation of a Memorable Tourism Experience Scale (MTES). Journal of Travel Research, 53(3): 323-335. DOI: $10.1177 / 0047287513496468$.

Kim J., Ritchie J.R.B and Mc Cormik B.M. (2012). Development of a Scale to Measure Memorable Tourism Experiences. Journal of Travel Research, 51(1): 12-25. DOI: $10.1177 / 0047287510385467$.

Ladhari R. (2007). The effect of consumption emotions on satisfaction and word-of mouth communications. Psychology and Marketing, 24(12): 1085-1108. DOI: 10.1002/mar.20195.

Lee J. and Kyle G.T. (2012). Recollection consistency of festival consumption emotions. Journal of Travel Research, 51(2): 178-190. DOI: 10.1177/ 0047287510394197. 
Liljander V. and Strandvik T. (1997). Emotions in service satisfaction. International Journal of Service Industry Management, 8(2): 148-169. DOI: 10.1108/09564239710166272.

Loureiro S.M. (2010). Satisfying and delighting the rural tourists. Journal of Travel and Tourism Marketing, 27(4): 396-408. DOI: 10.1080/10548408.2010.481580.

Manyiwa S., Priporas C.V. and Wang X.L. (2018). Influence of perceived city brand image on emotional attachment to the city. Journal of Place Management and Development, 11(1): 60-77. DOI: 10.1108/JPMD-01-2017-0011.

Martín-Ruiz D., Castellanos-Verdugo M. and de los Ángeles Oviedo-García M. (2010). A visitors' evaluation index for a visit to an archaeological site. Tourism Management, 31(5): 590-596. DOI: 10.1016/j.tourman.2009.06.010.

Mauss I.B. and Robinson M.D. (2009). Measures of emotion: A review. Journal Cognition and Emotion, 23(2): 209-237. DOI: 10.1080/02699930802204677.

Mcintosh A.J. and Siggs A. (2005). An Exploration of the Experiential Nature of Boutique Accommodation. Journal of Travel Research, 44(August): 74-81. DOI: 10.1177/0047287505276593.

Moreno G.S. and Ritchie J.B. (2009). Understanding the museum image formation process: A comparison of residents and tourists. Journal of Travel Research, 47(4), 480-493. DOI: 10.1177/0047287508326510.

Oliver R.L. (1997). Satisfaction: A Behavioral Perspective on the Consumer. New York: McGraw-Hill.

Oliver R.L. (1980). A cognitive model of the antecedents and consequences of satisfaction decisions. Journal of Marketing Research, 17(4): 460-469. DOI: $10.1177 / 002224378001700405$

Poria Y., Butler R and Airey D. (2003). The core of heritage tourism. Annals of Tourism Research, 30(1): 238-254. DOI: 10.1016/s0160-7383(02)00064-6.

Poria Y., Reichel A. and Biran A. (2006). Heritage site management: Motivations and expectations. Annals of Tourism Research, 33(1): 162-178. DOI: 10.1016/j.annals.2005.08.001.

Prayag G., Hosany S., Muskat B. and Del Chiappa G. (2015). Understanding the Relationships between Tourists' Emotional Experiences, Perceived Overall Image, Satisfaction, and Intention to Recommend. Journal of Travel Research, 114. DOI: $10.1177 / 0047287515620567$.

Prayag G., Hosany S., Muskat B. and Del Chiappa G. (2017), Understanding the Relationships between Tourists' Emotional Experiences, Perceived Overall Image, Satisfaction, and Intention to Recommend. Journal of Travel Research, 561. DOI: $10.1177 / 0047287515620567$.

Prayag G., Hosany S. and Odeh K. (2013). The role of tourists' emotional experiences and satisfaction in understanding behavioral intentions. Journal of Destination Marketing and Management, 2(2): 118-127. DOI: 10.1016/j.jdmm. 2013.05.001.

Reder L.M., Donavos D.K., and Erickson M.A. (2002). Perceptual Match Effects in Direct Tests of Memory: The Role of Contextual Fan. Memory and Cognition, 30(2): 312-23. DOI: 10.3758/bf03195292.

Scannell L. and Gifford R. (2010). Defining place attachment: A tripartite organizing framework. Journal of Environmental Psychology, 30(1): 1-10. DOI: 10.1016/ j.jenvp.2009.09.006. 
Thyne M. (2001). The importance of values research for not profit organizations: the motivation-based values of museum visitors. International Journal of Non Profit and Voluntary Sector Marketing, 6(2): 116-130. DOI: 10.1002/nvsm.140.

Torres E.N. and Kline S. (2006). From satisfaction to delight: A model for the hotel industry. International Journal of Contemporary Hospitality Management, 18: 290-301. DOI: 10.1108/09596110610665302.

Um S., Chon K. and Ro Y. (2006). Antecedents of revisit intention. Annals of Tourism Research, 33(4): 1141-1158. DOI: 10.1016/j.annals.2006.06.003.

Vecco M. (2010). A definition of cultural heritage: From the tangible to the intangible. Journal of Cultural Heritage, 11(3): 321-324. DOI: 10.1016/j.culher.2010.01.006.

Walters G. and Sparks B. (2012). The impact of consumption vision and emotion on the tourism consumer's decision behavior. Journal of Hospitality and Tourism Research, 36(3): 366-389. DOI: 10.1177/1096348010390815.

Walsh G., Shiu E., Hassan L.M., Michaelidou N. and Beatty S.E. (2011). Emotions, Store-Environmental Cues, Store-Choice Criteria, and Marketing Outcomes. Journal of Business Research, 64(7): 737-44. DOI: 10.1016/j.jbusres. 2010.07.008.

Westbrook R. and Oliver R. (1991). The dimensionality of consumption emotion patterns and consumer satisfaction. Journal of Consumer Research, 18(1): 8491. DOI: $10.1086 / 209243$.

Williams D.R., Patterson M.E., Roggenbuck J.W. and Watson A.E. (1992). Beyond the commodity metaphor: Examining emotional and symbolic attachment to place. Leisure Sciences, 14(1): 29-46. DOI: 10.1080/01490409209513155.

Wong A. (2004). The role of emotional satisfaction in service encounters. Managing Service Quality: An International Journal, 14(5): 365-376. DOI: 10.1108/ 09604520410557976.

Yuksel A. and Yuksel F. and Bilim Y. (2010). Destination Attachment: Effects on Customer Satisfaction and Cognitive, Affective and Conative Loyalty. Tourism Management, 31(2): 274-84. DOI: 10.1016/j.tourman.2009.03.007.

Yuksel A. and Yuksel F. (2007). Shopping Risk Perceptions: Effects on Tourists' Emotions, Satisfaction and Expressed Loyalty Intentions. Tourism Management, 28(3): 703-13. DOI: 10.1016/j.tourman.2006.04.025. 